\title{
Hepatitis B crónica
}

\author{
José Ignacio Gran S. ${ }^{l}$ y Alejandro Soza R. ${ }^{l}$
}

\section{Chronic B Hepatitis}

Chronic hepatitis B is a major public health problem, causing $30 \%$ of cirrhosis worldwide and up to $50 \%$ of hepatocellular carcinoma. In high prevalence regions, virus transmission is mainly vertical, which is associated with a risk of chronic disease in $90 \%$ of cases. The development of chronic hepatitis in adults is less than $5 \%$, but it could reach up to $30 \%$ in patients with immunosuppression. In the evaluation of subjects with $\mathrm{HBV}$ infection is recommended to investigate risk factors for progression to cirrhosis and hepatocellular carcinoma, test for sexually transmitted infections and control liver comorbidities that will affect patient's prognosis, such as chronic alcohol consumption, nonalcoholic fatty liver disease and coinfection with hepatitis C and HIV. Management of patients with chronic hepatitis B includes testing and prevention for contacts, control of comorbidities, and specific treatment with antivirals when indicated. Treatment with nucleotide/ nucleoside analogues is considered of choice as they are safe, achieves adequate control of viral replication and reduces the risk of liver complications. The goal of the WHO is to achieve a significant decrease in the prevalence of hepatitis B by 2030 through preventive measures in regions with a high prevalence of the disease.

Key words: Hepatitis B, cirrhosis, nucleotide analogs, interferon.

\section{Resumen}

La infección por el virus de la hepatitis B (VHB) es un importante problema de salud pública, estimándose que causa $30 \%$ de los casos de cirrosis a nivel mundial y hasta 50\% de los hepatocarcinomas. En las regiones de alta prevalencia, la transmisión del virus es principalmente vertical, la que se asocia a un riesgo de cronificación de hasta $90 \%$. Por el contrario, el desarrollo de hepatitis crónica en adultos es menor de 5\% y en inmunosupresión puede alcanzar hasta 30\%. En la evaluación de sujetos con infección por VHB es necesaria pesquisar factores de riesgo de progresión a cirrosis y hepatocarcinoma, detectar otras infecciones de transmisión sexual y controlar comorbilidades hepáticas que afectarán el pronóstico del paciente, como el consumo crónico de alcohol, el hígado graso no alcohólico o la coinfección con hepatitis C y VIH. El manejo de los pacientes con hepatitis B crónica requiere preocuparse del testeo y medidas de prevención para los contactos, control de comorbilidades y tratamiento específico con antivirales cuando existe indicación. El tratamiento con análogos de nucleótidos/ nucleósidos se considera de elección al ser seguro, lograr un adecuado control de la replicación viral y disminuir riesgo de complicaciones hepáticas. El objetivo de la OMS es lograr una disminución significativa de la prevalencia de la hepatitis B el año 2030 a través de medidas preventivas en regiones de alta prevalencia de la enfermedad.

Palabras clave: Hepatitis B, cirrosis, análogos nucleótidos, interferón.
'Departamento de Gastroenterología, Pontificia Universidad Católica de Chile. Santiago, Chile.

Recibido: 4 de julio de 2020

Aceptado: 10 de julio de 2020

Correspondencia a: Alejandro Soza Ried Profesor Titular

Departamento de Gastroenterología, Pontificia Universidad Católica de Chile. Diagonal Paraguay 362. $4^{\circ}$ piso. Santiago, Chile asoza@med.puc.cl

\section{Introducción}

La infección por el virus de la hepatitis B (VHB) es un importante problema de salud pública a nivel mundial, es la causa de aproximadamente el 30\% de las de cirrosis y hasta $50 \%$ de los hepatocarcinomas en el mundo ${ }^{1}$. Se estima que unos 2 mil millones de sujetos han presentado la infección, de los cuales 260 millones desarrollaron infección crónica por VHB. La mortalidad relacionada al virus se calcula cercana a 1 millón de sujetos al año, derivado principalmente de las complicaciones de la cirrosis. Con un programa preventivo y de tratamiento a escala mundial, la OMS se ha planteado el objetivo ambicioso de eliminar las hepatitis virales como amenaza para la salud pública para el año $2030^{2}$. 


\section{Fisiopatología}

El VHB es un virus ADN de la familia Hepadnaviridae, de la que es su principal representante. Tiene un genoma pequeño de 3.200 pares de bases que se organiza en 4 marcos de lectura abierta parcialmente superpuestos que codifican para 7 proteínas, entre ellas los antígenos de superficie (HBsAg), nuclear o core $(\mathrm{HBcAg})$, antígeno de la envoltura $(\mathrm{HBe} A g)$, proteína $\mathrm{X}$ (un transactivador, relevante en hepatocarcinogénesis) y la enzima polimerasa, que tiene actividad de transcriptasa reversa ${ }^{1}$.

La transmisión del virus puede ocurrir en forma vertical, vía parenteral, percutánea o por contacto sexual. Este virus ingresa al hepatocito mediante endocitosis, uniéndose a un receptor de membrana específico del hepatocito (el polipéptido cotransportador de sodio taurocolato; NTCP). Luego se traslada al núcleo donde los mecanismos de reparación modifican el ADN viral desde una conformación circular laxa a uno circular covalente cerrado (ccc), en esta conformación se incorpora al genoma del hospedero. El ADN ccc activa la maquinaria transcripcional para la producción ARN que sirve de mensajero para traducción de las proteínas virales y también como templado pregenómico que por transcripción reversa forma el ADN genómico. El ARN pregenómico y la polimerasa se unen con la proteína core para formar la nucleocápside. Por otro lado, el HBsAg se une a membranas en el retículo endoplásmico, donde además de ensamblarse con la nucleocápside para formar partículas virales completas que se secretan por exocitosis, se forman partículas esféricas y tubulares en exceso que se excretan como partículas virales incompletas no viables ${ }^{3}$. La presencia de dichos antígenos estimula el sistema inmune con producción de citoquinas inflamatorias, liberación de anticuerpos neutralizantes y activación de linfocitos T citotóxicos, los que producen apoptosis y efecto citolítico directo de los hepatocitos infectados. Los linfocitos T citotóxicos son los principales responsables de la respuesta inmune.

El daño hepatocelular y las manifestaciones clínicas de la enfermedad se encuentran relacionados a la magnitud de la reacción inflamatoria asociada. En los sujetos con infección crónica existe una disfunción cuantitativa o cualitativa del linfocito $\mathrm{T}$, lo que impide la completa eliminación del virus y su persistencia en el organismo ${ }^{4}$.

Se describen 10 genotipos (designados de la A a la J) y numerosos subtipos, lo que tienen distribución geográfica característica. En Sudamérica y Chile predomina el genotipo F. Se han descrito asociaciones entre los genotipos con la probabilidad de seroconversión espontánea (mayor en genotipo $\mathrm{B}$ que $\mathrm{C}$ ), la respuesta a tratamiento con interferón (mejor en genotipo A y B que C y D) y el riesgo de hepatocarcinoma, sin embargo, no hay evidencia de que afecte la respuesta a los nucleós(t)idos análogos. Por lo anterior, la utilidad de su determinación en la práctica clínica habitual es limitada.

Se han descrito una serie de mutaciones que pueden tener relevancia clínica. Por ejemplo, el tratamiento con antivirales orales puede seleccionar poblaciones virales con mutaciones en la polimerasa que permitan escape al antiviral. Dado que hay superposición entre el marco de lectura abierta entre HBsAg y el gen de la polimerasa, estas mutaciones pueden llevar a generar variantes en el gen de HBsAg que se pueden manifestar en falla en la detección de HBsAg por exámenes diagnósticos comerciales o, aún más preocupante, a generar variantes de escape frente a vacunas. Otras mutaciones frecuentes ocurren en la región precore, responsable de la producción de $\mathrm{HBeAg}$. Los pacientes con estas mutaciones tienen replicación viral activa, con el fenotipo de hepatitis $\mathrm{B}$ crónica, antígeno e negativo.

\section{Historia natural}

De los pacientes adultos contagiados sólo el 5\% desarrolla una infección crónica, sin embargo, esto aumenta a $30 \%$ en quienes presentan un estado de inmunosupresión y hasta $50 \%$ en los menores de 5 años. En la transmisión vertical el desarrollo de una infección crónica ocurre en hasta $90 \%$, siendo la principal forma de transmisión en los países de alta prevalencia ${ }^{5}$.

En países con elevada endemia, el riesgo de progresión a cirrosis sin tratamiento es de $8-20 \%$ a los 5 años y el riesgo de hepatocarcinoma (HCC) es de $2-5 \%$ anual. Es importante destacar que el riesgo de HCC se encuentra elevado incluso en los sujetos sin cirrosis, siendo cercano al $3 \%$ a 5 años ${ }^{1,3}$. Por último, existe $10 \%$ de coinfección con hepatitis $\mathrm{C}, 5 \%$ con hepatitis $\mathrm{D}$ y $10 \%$ con $\mathrm{VIH}^{6,7}$.

\section{Factores de riesgo de progresión}

Períodos prolongados de hepatitis se relacionan a mayor riesgo de progresión a cirrosis y hepatocarcinoma. Por lo mismo, la transmisión en etapas tempranas de la vida, la presencia de carga viral elevada y períodos de hepatitis prolongados son importantes factores de riesgo ${ }^{3,7}$. De la misma manera la persistencia de $\mathrm{HBeAg}$, que se correlaciona con elevada replicación viral, se asocia a mayor riesgo de cirrosis ${ }^{1}$. Otros factores de riesgo son el sexo masculino, historia familiar de cirrosis, la coinfección con virus de la hepatitis $\mathrm{C}$ o VIH, el consumo crónico de alcohol e hígado graso metabólico concomitante ${ }^{8}$. 


\section{Fases de la enfermedad}

Actualmente, se determina la etapa de la hepatitis $\mathrm{B}$ crónica según evidencia bioquímica o histológica de hepatitis y el estado del antígeno e, el que refleja una elevada replicación viral y en cierto grado temporalidad de la enfermedad ${ }^{1,3}$. Se definen 5 etapas (Figura 1):

- Infección crónica con antígeno "e" positivo: Etapa de tolerancia inmune, se caracteriza por presentar carga viral muy elevada con transaminasas normales. Se observa en sujetos que se infectan al nacer (pudiendo durar hasta la adolescencia o adultez joven) e inmunosuprimidos. En sujetos que se infectan siendo adultos esta etapa puede ser breve o inexistente.

- Hepatitis crónica con antígeno "e" positivo: Hay evidencia de inflamación hepática con transaminasas muy elevadas y necroinflamación en la histología, acumulación de fibrosis y disminución de la carga viral por aclaramiento inmune. En este período es de utilidad el tratamiento antiviral.

- Infección crónica con antígeno "e" negativo: Es un estado de negativización del antígeno e con bajos niveles de carga viral y transaminasas normales. Es un estado de mínima replicación llamado también portador inactivo. Puede reactivarse, por ejemplo, ante episodios de inmunosupresión.

- Hepatitis crónica con antígeno "e" negativo: Esta etapa se caracteriza por la activación de la enfermedad en presencia de mutaciones precore que impiden la producción de $\mathrm{HBeAg}$, pero con replicación viral activa, aminotransferasas elevadas e inflamación hepática en la biopsia. También tiene utilidad el tratamiento antiviral en esta etapa.
- HBsAg negativo: Asintomático y con carga viral no detectable. Estos pacientes se identifican por la positividad del anti-HBc en ausencia de HBsAg. Es relevante identificarlos por la posibilidad de recaída ante inmunosupresión severa, especialmente con rituximab o terapia de acondicionamiento pretrasplante de médula.

\section{Clínica}

Los síntomas de la infección viral son variables. Luego del contagio el $35 \%$ presenta una hepatitis ictérica, $65 \%$ es asintomático y entre 0,1 al $0,5 \%$ de los casos se puede presentar como insuficiencia hepática aguda ${ }^{3}$. Las manifestaciones extrahepáticas se observan en $10 \%$ de los casos, principalmente glomerulopatías, artritis y poliarteritis nodosa ${ }^{9}$. En estados avanzados de la enfermedad se manifiestan las complicaciones de la cirrosis como hemorragia digestiva variceal, ascitis y encefalopatía. Es importante en la aproximación clínica inicial observar los estigmas de cirrosis al examen físico, como arañas vasculares, palma hepática y esplenomegalia.

\section{Serología}

- HBsAg: Sello de la infección. La persistencia de este antígeno en sangre por más de 6 meses define la hepatitis crónica.

- Anticuerpos anti-HBc totales: Representa exposición pasada o presente al virus, compuesto por IgG $\mathrm{y} / \mathrm{o}$ IgM. Ante su positividad se complementa con anticuerpos IgM anti-HBc para definir adecuada-

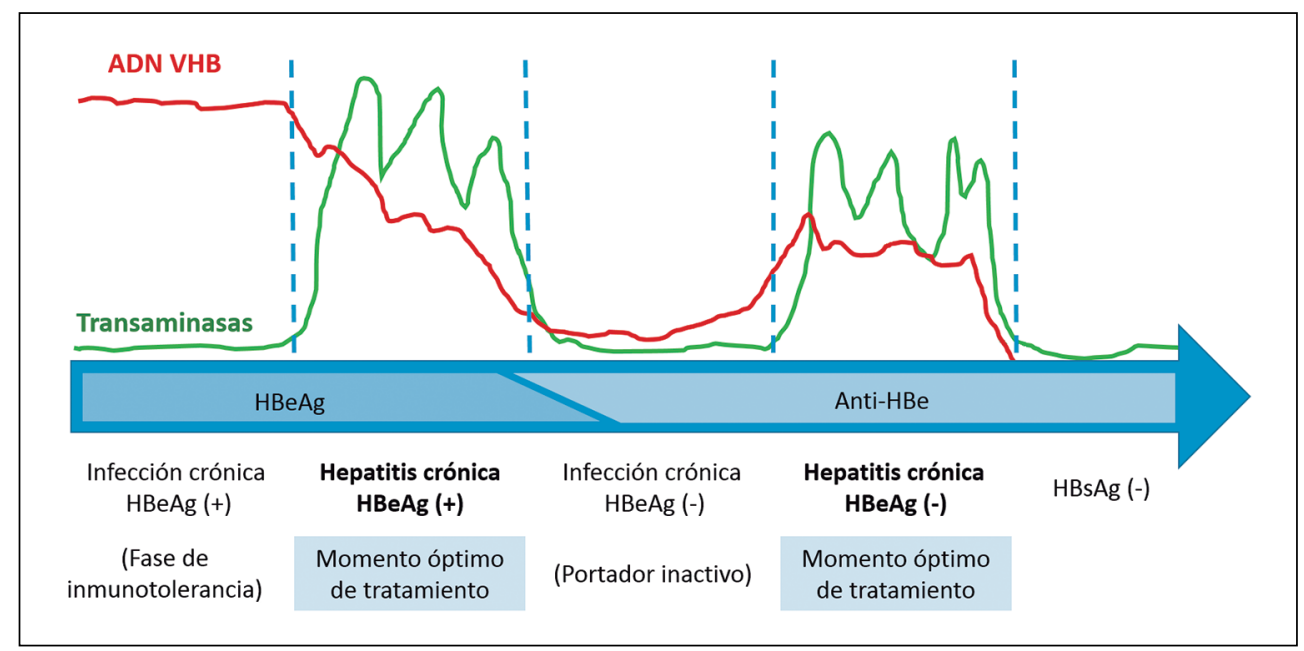

Figura 1. Etapas de la hepatitis B crónica. La determinación de la etapa de la enfermedad depende de la elevación de transaminasas, niveles de ADN de hepatitis $B$, presencia del antígeno e y anticuerpos antiantígeno e. HBeAg: Antígeno de envoltura de hepatitis B. HBsAg: Antígeno de superficie de hepatitis B. Anti-HBe: Anticuerpos antiantígeno e. Adaptado de ref 3. 
mente su temporalidad. Indica exposición al virus, pero no es un anticuerpo neutralizante, por lo que no indica inmunidad.

- Anti-HBs: Marcador de inmunidad natural o por vacuna contra el virus, se presentan en el $90 \%$ de los pacientes previamente expuestos. Es un anticuerpo neutralizante.

- ADN VHB: Indicador de actividad replicativa del virus, útil para indicar tratamiento y en la evaluación al tratamiento antiviral. Su medición cuantitativa se conoce habitualmente como "carga viral" y se determina por PCR cuantitativa, expresándose en unidades internacionales (UI) por $\mathrm{mL}$.

- HBeAg: Se correlaciona con replicación viral, predice niveles elevados de DNA viral en sangre. Permite determinar el estadio de la enfermedad crónica según lo ya descrito.

- Anti-HBe: Se observa al negativizar el HBeAg, es un marcador de baja replicación y de control inmunológico, una etapa denominada "portador inactivo".

\section{Evaluación}

En los pacientes con infección por VHB es necesaria una adecuada anamnesis con un examen físico completo pesquisando síntomas, factores de riesgo de infección y progresión, y elementos sugerentes de cirrosis. Dentro de los exámenes son necesarias las pruebas hepáticas, HBsAg para demostrar presencia del virus, serología anti-HBc para definir temporalidad y marcadores de replicación viral como HBeAg, anti-HBe y DNA de VHB. Para la evaluación de fibrosis hepática la biopsia ha sido prácticamente reemplazada por técnicas no invasivas como la elastografía transiente (Fibroscan ${ }^{\circledR}$ ), las que se correlacionan adecuadamente con el grado de fibrosis ${ }^{10}$. Además, se debe estudiar la presencia de otras infecciones de transmisión sexual con serología para VIH, anticuerpos antivirus hepatitis C y RPR o VDRL para sífilis. Por último, en los pacientes con cirrosis y en sujetos con factores de riesgo como antecedentes familiares, es necesario realizar tamizaje para $\mathrm{HCC}$.

\section{Tamizaje}

Se sugiere realizar tamizaje de VHB con $\mathrm{HBsAg}$ y anti-HBc en los siguientes casos ${ }^{11}$ :

- Embarazadas.

- Sujetos que provengan de países de moderada o alta prevalencia $(>2 \%)$.

- Contactos de personas que viven con un portador crónico.
- Personas con factores de riesgo: varias parejas sexuales, infección por VIH, privados de libertad, personal de salud y hemodiálisis.

- Previo al inicio de terapia inmunosupresora.

\section{Tratamiento}

Como medidas generales se sugiere evitar el consumo de alcohol, control del sobrepeso, el estudio de comorbilidades hepáticas y pesquisa activa de infecciones de transmisión sexual. En el caso de presentarse en etapa de cirrosis realizar su manejo habitual con pesquisa y tratamiento de várices esofágicas, manejo de ascitis y encefalopatía hepática, tamizaje de HCC y una adecuada nutrición.

Para evitar el contagio del virus a terceros se sugieren las siguientes medidas ${ }^{11}$ :

- Vacunación para los contactos con HBsAg negativo.

- Utilizar métodos de barrera con la pareja.

- No compartir afeitadora, cepillo de dientes ni equipo de inyección.

- No donar sangre.

- Cubrir heridas superficiales.

\section{Objetivos del tratamiento antiviral}

Si bien la cura virológica es el objetivo teórico ideal, actualmente, es rara vez logrado debido a la integración del ADN viral en el genoma del hospedero. Se denomina "cura funcional" a la negativización sostenida del HBsAg, lo se relaciona a mínima progresión a cirrosis y HCC por lo que es un resultado deseable, sin embargo, se logra en apenas el 10\% de los casos con el uso de interferón y con antivirales orales. Por último, la "cura parcial" es un estado que se puede alcanzar con mayor probabilidad con los tratamientos antivirales actuales y se asocia a baja tasa de replicación, hepatitis, menor progresión a cirrosis y HCC. Esta consiste en la negativización del $\mathrm{HBeAg}$ con desarrollo de anticuerpos anti $\mathrm{HBe}$, transaminasas normales y carga viral indetectable ${ }^{1}$.

\section{Indicaciones de tratamiento}

Según las recomendaciones de la EASL 2017¹, la decisión de iniciar tratamiento se basa en 3 aspectos fundamentales: La carga viral de VHB, las transaminasas y la gravedad de la enfermedad hepática. Se sugiere iniciar tratamiento en los siguientes casos:

- Insuficiencia hepática aguda.

- Cirrosis con ADN de VHB detectable en cualquier rango. 
- Hepatitis crónica con transaminasas elevadas, necroinflamación en la biopsia y niveles de DNA mayores de $2.000 \mathrm{UI} / \mathrm{mL}$.

- Carga viral mayor de $20.000 \mathrm{UI} / \mathrm{mL}$ con elevación de transaminasas independiente del resultado de la biopsia.

- Previo al uso inmunosupresores.

- Se sugiere considerar tratamiento en pacientes con antecedentes familiares de HCC, manifestaciones extrahepáticas y cuando hay niveles de ADN persistentemente sobre $20.000 \mathrm{UI} / \mathrm{mL}$ con transaminasas normales.

\section{Opciones de tratamiento}

Se utilizan medicamentos que tengan efecto antiviral efectivo para lograr cura funcional o parcial. Existen principalmente dos alternativas de tratamiento, el interferón y los análogos nucleósidos (entecavir $0,5 \mathrm{mg}$ al día) o nucleótidos (tenofovir $300 \mathrm{mg}$ al díal tenofovir alafenamida $25 \mathrm{mg}$ al día). Estos fármacos bloquean la polimerasa viral con alta afinidad y tienen alta barrera genética, lo que se traduce en selección de mutaciones de resistencia a la terapia en forma muy excepcional. Lo anterior permite su uso como monoterapia, a diferencia de lo que se requiere en el tratamiento de VIH o de la hepatitis C.

Las ventajas de los análogos son que se administran por vía oral, presentan buen perfil de seguridad y un alto control de la replicación viral. En general logran la negativización del $\mathrm{HBeAg}$ en $20 \%$ de los casos al año, la disminución significativa de la carga viral en la mayoría de los pacientes y la normalización de las transaminasas entre $60-70 \%{ }^{1}$. Su desventaja es que requieren ser administrados por un período indefinido de tiempo, muchas veces a permanencia debido a que su suspensión se asocia a recaídas una gran proporción de los pacientes. La negativización del HBsAg es excepcional con estas terapias.

Las ventajas del interferón (actualmente peginterferón) son que se administra por tiempo definido (48 semanas) y que logra la negativización del HBsAg hasta en 10\%. Las desventajas son su administración subcutánea y sus efectos adversos: trastornos psiquiátricos, síntomas $f l u$-like, neutropenia, trombocitopenia $\mathrm{y}$ alteraciones tiroídeas ${ }^{11}$.

Se debe seleccionar el tratamiento según cada paciente considerando su edad, comorbilidades y objetivos terapéuticos.

Se está investigando activamente en una serie de nuevas estrategias de tratamiento que permitan un control más definitivo de la infección, idealmente logrando erradicar o silenciar el cccADN. Estos incluyen inhibidores de la entrada, silenciamiento genético con RNA de interferencia y modulación inmune, entre otros.

\section{Seguimiento}

En los pacientes con hepatitis B crónica se sugiere controlar por el especialista con pruebas hepáticas, función renal, glicemia, electrolitos y $\mathrm{ADN}$ viral cada 3 meses. En los casos en que se utiliza peginterferón, además de lo anterior, se requiere seguimiento con hemograma y función tiroídea. Luego de lograr niveles indetectables de ADN se sugiere controlar cada 6 meses $^{11}$.

Se requiere además realizar tamizaje para $\mathrm{HCC}$ cada 6 meses en pacientes con cirrosis y una vez al año en pacientes sin cirrosis pero con factores de riesgo, como antecedentes familiares de $\mathrm{HCC}^{1}$.

En los pacientes sin cirrosis que logran la seroconversión del HBeAg y especialmente del HBsAg, aunque controversial podría suspenderse el tratamiento con análogos si se mantienen por un año de seguimiento con niveles de ADN indetectables y transaminasas normales. Al contrario, se sugiere no suspender el tratamiento en enfermos con cirrosis, postrasplante hepático o si inició tratamiento con el HBeAg negativo ${ }^{3}$.

\section{Prevención}

La principal medida preventiva es la vacunación, la que es efectiva en un $90 \%$ de los sujetos inmunocompetentes. Los programas de vacunación universal en países de alta prevalencia han demostrado la disminución de la hepatitis B crónica, hepatocarcinoma y hepatitis aguda, por lo que se considera una importante herramienta para lograr el control de la enfermedad. Se recomienda su uso en contactos sexuales de portadores de VHB, personal de salud y otros grupos de riesgo como pacientes en hemodiálisis ${ }^{11,12}$. Las vacunas disponibles en la actualidad son en base al antígeno de superficie recombinante y requieren 3 dosis (esquema habitual: 0, 1 y 6 meses). Actualmente, se recomienda que esta vacuna se administre en forma universal a la población en los calendarios de vacunación con una primera dosis al momento de nacer. Esta es una de las medidas claves para lograr el objetivo de la eliminación de la hepatitis B como amenaza para la salud pública al año 2030 , definida como reducción de nuevos casos en $90 \%$ disminución de mortalidad en $65 \%$. Las otras medidas incluyen la prevención de la transmisión vertical, la seguridad de la sangre e inyecciones, reducción del daño en usuarios de drogas intravenosas y testeo/tratamiento.

\section{Pronóstico}

La hepatitis B es una condición frecuente en el mundo que conlleva elevada morbimortalidad y cos- 


\section{Artículo de Revisión}

tos en salud. Lo que define un peor pronóstico es la evolución a cirrosis, la que ocurre hasta en $30 \%$ de los pacientes, con riesgo de descompensación y de desarrollo de hepatocarcinoma. Otros factores que se asocian con peor pronóstico son la presencia de comorbilidades hepáticas, el consumo crónico de alcohol, la esteatohepatitis no alcohólica y la coinfección con otros virus como el VHC y VIH. Con la incorporación universal de la vacuna para el VHB se espera una disminución significativa de la carga de enfermedad de esta infección y de sus complicaciones asociadas.

\section{Agradecimientos}

Trabajo financiado parcialmente por proyecto Fondecyt $\mathrm{N}^{\circ} 1191389$ (AS).

\section{Referencias}

1.- European Association for the Study of the Liver. EASL 2017 clinical practice guidelines on the management of hepatitis B virus infection. J Hepatol 2017;67:370-98.

2.- The Lancet. Towards elimination of viral hepatitis by 2030. Lancet 2016;388:308.

3.- Tang L, Covert E, Wilson E, Kottilil S. Chronic Hepatitis B Infection: A Review. JAMA. 2018;319:1802-13.

4.- Seto W, Lo Y, Pawlotsky J, Yuen M. Chronic hepatitis B virus infection. Lancet. 2018;3922313-24.

5.- Chen C, Yang H. Natural history of chronic hepatitis B revealed. J Gastroenterol Hepatol. 2011;26:628-38.
6.- Parkin D. The global health burden of infection-associated cancers in the year 2002. Int J Cancer. 2006;118:3030-44.

7.- Poh Z, Goh B, Chang P, Tan C. Rates of cirrhosis and hepatocellular carcinoma in chronic hepatitis B and the role of surveillance. Eur J Gastroenterol Hepatol. 2015;27:638-43.

8.- Yang H, Lee M, Liu J, Chen C. Risk calculators for hepatocellular carcinoma in patients affected with chronic hepatitis B in Asia. World J Gastroenterol. 2014;20:6244-51.

9.- Liang T. Hepatitis B: the virus and disease. Hepatology. 2009;49(suppl):S13-S21.
10.- Castera L. Hepatitis B: are non-invasive markers of liver fibrosis reliable? Liver Int. 2014;34 Suppl 1:91-6.

11.- Terrault N, Lok AS, McMahon B, Chang K, Hwang J, Jonas M, et al. Update on prevention, diagnosis, and treatment of chronic hepatitis B AASLD 2018 hepatitis B guidance. Hepatology. 2018;67:1560-99.

12.- Lee C, Gong Y, Brok J, Boxall EH, Gluud C. Effect of hepatitis B immunisation in newborn infants of mothers positive for hepatitis B surface antigen: systematic review and meta-analysis. BMJ 2006;332:32836. 